\title{
Serine Palmitoyltransferase 1
}

National Cancer Institute

\section{Source}

National Cancer Institute. Serine Palmitoyltransferase 1. NCI Thesaurus. Code C127890.

Serine palmitoyltransferase 1 (473 aa, $\sim 53 \mathrm{kDa}$ ) is encoded by the human SPT LC1 gene.

This protein plays a role in the biosynthesis of sphingolipids. 